\title{
Audiological Functions in Pregnancy
}

\author{
${ }^{1}$ Ashok Verma, ${ }^{2}$ Rakesh Thakur, ${ }^{3}$ Sunder S Dogra, ${ }^{4}$ Shivani Sharma, ${ }^{5}$ Amrita Singhal
}

\section{ABSTRACT}

Introduction: During pregnancy virtually every organ system undergoes anatomical and physiological changes that can alter appreciably the criteria for diagnosis and treatment of diseases. Hormonal fluctuations alter the composition of endolymph and perilymph, and ion transport process. Hence, audiological functions in pregnancy need evaluation.

Materials and methods: After approval of Institutional Ethics Committee, 100 pregnant women were recruited in the 1 st trimester. Tuning tests were done using 128, 256, 512, and $1024 \mathrm{~Hz}$ tuning forks. Pure tone audiometry was done and hearing thresholds measured for 125, 250, 500, 1000, 2000, and $4000 \mathrm{~Hz}$. Finally, impedance audiometry was done in all the women in each trimester.

Results: There was no air-bone gap. There was gradual reduction in hearing acuity at low frequencies $(125,250,500$, and $1000 \mathrm{~Hz}$ ) from 1st to 3rd trimester of pregnancy. The hearing thresholds got stabilized in the 3rd trimester and returned to normal in postpartum period. For $2000 \mathrm{~Hz}$ and higher frequencies, there was no significant difference in relation to pregnant subjects. Number of pregnancies did not affect the audiological functions.

Conclusion: Low-frequency hearing loss during pregnancy appears to be transient in nature with complete resolution in the postpartum period in most cases. For better understanding of these changes, obstetricians and otolaryngologists can team-up and avoid use of drugs for their symptoms during pregnancy.

Keywords: Hearing loss, Impedance audiometry, Pregnancy, Pure tone audiometry.

How to cite this article: Verma A, Thakur R, Dogra SS, Sharma S, Singhal A. Audiological Functions in Pregnancy. J South Asian Feder Obst Gynae 2017;9(1):42-46.

Source of support: Nil

Conflict of interest: None

Date of received: 22 September 2016

Date of acceptance: 16 November 2016

Date of publication: January 2017

\footnotetext{
${ }^{1}$ Associate Professor, ${ }^{2,5}$ Junior Resident, ${ }^{3}$ Professor, ${ }^{4}$ Speech Therapist and Audiometrist

1,5 Department of Obstetrics and Gynecology, Dr. Rajendra Prasad Government Medical College, Kangra, Himachal Pradesh, India

${ }^{2-4}$ Department of Otorhinolaryngology, Head and Neck Surgery Dr. Rajendra Prasad Government Medical College, Kangra Himachal Pradesh, India

Corresponding Author: Ashok Verma, Associate Professor Department of Obstetrics and Gynecology, Dr. Rajendra Prasad Government Medical College, Kangra, Himachal Pradesh, India e-mail: dr.ashok_verma@yahoo.com
}

\section{INTRODUCTION}

The anatomical, physiological, and biochemical adaptations to pregnancy are profound. During normal pregnancy, virtually every organ system undergoes anatomical and physiological changes that can alter appreciably the criteria for diagnosis and treatment of diseases. Without understanding of these adaptations to pregnancy, it is almost impossible to understand the disease process that can threaten during pregnancy. A number of physiological changes occur during pregnancy; among them audiological changes are quite significant. ${ }^{1}$

These changes are mainly due to the changing levels of sex hormones and return to normal once pregnancy is over. The hormonal alterations which happen during the menstrual cycle, gestation, and menopause can result in changes in the homeostasis of labyrinthine fluids since they have a direct influence on the enzymatic process and the action of neurotransmitters. ${ }^{2}$

While creating optimal conditions for pregnancy, these hormonal changes cause an increase of $6.5 \mathrm{~L}$ in extracellular and 1.25 L in intracellular fluids. As a result of these osmotic changes in body, water and sodium retention takes place. It is evident from previous studies that circulating sex hormones affect the sensorineural hearing and one may expect changes in hearing levels with so much fluid retention during pregnancy. ${ }^{1}$

Hormone fluctuations alter the maintenance of the chemical composition of both perilymph and endolymph in the inner ear, and the ion transport processes between them. Therefore, patency of cochlear aqueduct is key to whether the effect on hearing will be to a greater or lesser extent, with the changes in composition and pressure of the cerebrospinal fluid during pregnancy. ${ }^{3}$

Despite various advances in audiology there appears to be little research in audiological changes observed in pregnancy and thereafter in the postpartum period.

Review of the literature revealed very few studies where audiological changes in pregnancy have been studied. We therefore, conducted this study at the Department of Obstetrics and Gynecology, Dr. Rajendra Prasad Government Medical College, Kangra, Himachal Pradesh, India in association with the Department of Otorhinolaryngology, to assess the changes in audiological functions occurring in pregnancy and 6 to 10 weeks after delivery. 


\section{AIMS AND OBJECTIVES}

To study the audiological functions in pregnancy.

\section{MATERIALS AND METHODS}

The prospective study was conducted on antenatal women attending the outpatient department at the Department of Obstetrics and Gynecology, in association with the Department of Otorhinolaryngology, Head and Neck Surgery of Dr. Rajendra Prasad Government Medical College, Kangra at Tanda over a duration of 18 months.

The sample size consisted of 100 pregnant women belonging to the 20 to 35 years age group.

All the antenatal women were subjected to detailed ear, nose, throat (ENT) and physical examination and findings were recorded.

\section{Inclusion Criteria for the Selection of Case}

- Antenatal women in age group of 20 to 35 years

- Normal ENT examination

- No ENT complaints before pregnancy

- No use of drugs during pregnancy

- Nondiabetic and nonhypertensive

- No systemic disease

- No family history of hearing loss.

\section{Exclusion Criteria}

- Patient's refusal

- Antenatal women with ENT complaints prior to pregnancy

- Antenatal women with history of diabetes mellitus, hypertension, history of smoking, alcohol intake, drug intake, head injury

- High-risk pregnancy.

\section{Study Design}

It was a prospective study. The antenatal women selected were investigated periodically in each of the four groups, according to the classification after fulfilling the inclusion and exclusion criteria:

Group I: 1 to 12 weeks (1st trimester)

Group II: 13 to 28 weeks (2nd trimester)

Group III: 29 to 42 weeks (3rd trimester)

Group IV: Postpartum up to 3 months after pregnancy.

\section{Methodology}

The study started after obtaining the approval of Institutional Ethics Committee and Scientific and Protocol Committees.

\section{Study Procedure}

The study procedure was explained to antenatal women enrolled for the study and thereafter written consent was taken. Detailed history, systemic examination, complete clinical examination of ENT were done. A case record form filled for each patient. Tuning fork tests were performed using 128, 256, 512, and $1024 \mathrm{~Hz}$ tuning fork. Then pure tone audiometry (PTA) was done and hearing threshold was measured for 125, 250, 500, 1000, 2000, 4000 , and $8000 \mathrm{~Hz}$ frequencies for air conduction. Bone conduction threshold was measured for frequencies 250 , 500, 1000, 2000, and $4000 \mathrm{~Hz}$. ALPS advanced digital audiometer AD2100 was used for PTA. Finally, the impedance audiometry done. Impedance audiometer AT235 was used for performing tympanometry.

All tests were conducted with antenatal women comfortably seated in a sound isolated room where the background sound was below the accepted level.

\section{Method of Performing PTA}

An audiometer is an electronic device which produces pure tones, the intensity of which can be increased or decreased in $5 \mathrm{~dB}$ steps. Usually air conduction thresholds are measured for tones of 125, 250, 500, 1000, 2000, 4000, and $8000 \mathrm{~Hz}$ and bone conduction threshold for 250, 500, 1000, 2000, and $4000 \mathrm{~Hz}$. The amount of intensity that has to be raised above normal level is a measure of the degree of the hearing impairment at that frequency. The threshold of bone conduction is a measure of cochlear function. The difference in the threshold of air and bone conduction (A-B) gap is a measure of conductive deafness. Audiometer is so calibrated that hearing of a normal person both for air and bone conduction is at $0 \mathrm{~dB}$ and there is no A-B gap. ALPS advanced digital audiometer AD2100 was used for PTA.

Data was collected and entered in MS Excel 2007.

Repeated measure analysis of variance test was applied in order to test the significance of hearing for PTA.

\section{OBSERVATIONS}

Demographic characteristics of the women studied are shown in Table 1.

The mean pure PTA threshold of pregnant women in each ear and in each trimester, and 6 weeks after delivery is shown in Table 2.

As there was no air-bone gap, only air conduction thresholds were given. As shown in Table 2, there is a gradual decrease in hearing acuity at low frequencies (125, 250, 500 , and $1000 \mathrm{~Hz}$ ) from 1st to 3rd trimester of pregnancy.

The hearing thresholds got stabilized in the 3rd trimester and returned to normal in postpartum period. Furthermore, it was observed that there was a highly 
Table 1: Demographic characteristics

\begin{tabular}{lll}
\hline & No (Percentage) & Mean, range \\
\hline Age (years) & & \\
$20-25$ & $40(40)$ & $28.6 \pm 6.7$ \\
$26-30$ & $30(30)$ & Range $=15$ \\
$31-35$ & $30(30)$ & \\
Gravida & & $2.2 \pm 2.4$ \\
1 & $40(40)$ & Range $=5$ \\
2 & $30(30)$ & \\
3 or more & $30(30)$ & \\
Occupation & & \\
Teachers & $20(20)$ & \\
Laborer & $20(20)$ & \\
Nurses & $25(25)$ & \\
Housewives' & $35(35)$ & \\
Address & & \\
Rural & $60(60)$ & \\
Urban & $40(40)$ & \\
\hline
\end{tabular}

statistically significant difference of threshold during pregnancy (groups I, II, and III) from the postpartum (group IV). During this study, it has been observed that the threshold for low frequencies revealed a statistically significant difference in relation to pregnant subjects $(\mathrm{p}<0.05)$.

For 125 to $1000 \mathrm{~Hz}$, the postpartum (group IV) showed a highly statistically significant difference from the 1st to 3rd trimesters (groups I, II, and III respectively) $(p<0.05)$. For $2000 \mathrm{~Hz}$ and higher frequencies, there was no significant difference between the trimesters, postpartum.

The audiological changes that occur during pregnancy were not affected by the number of pregnancies in women. Statistical values were not significant $(p>0.05)$ between gravida I and II or more. Pregnancy did not affect the hearing acuity at high frequencies.

Table 2: Mean PTA threshold at various frequencies in right ear and left ear

\begin{tabular}{|c|c|c|c|c|}
\hline \multirow[b]{2}{*}{ Variable } & \multicolumn{2}{|l|}{ Right ear } & \multicolumn{2}{|l|}{ Left ear } \\
\hline & Mean $\pm S D$ & $\begin{array}{l}p \text {-value from } \\
\text { trimester } 1\end{array}$ & Mean $\pm S D$ & $\begin{array}{l}p \text {-value from } \\
\text { trimester } 1\end{array}$ \\
\hline \multicolumn{5}{|l|}{ PTA at $125 \mathrm{Hzs}$} \\
\hline PTA AC 125 1st trimester & $20.00 \pm 3.178$ & - & PTA Lt AC 125 1st trimester & - \\
\hline PTAAC 125 2nd trimester & $22.00 \pm 2.462$ & 0.00 & PTA Lt AC 125 2nd trimester & 0.00 \\
\hline PTAAC 125 3rd trimester & $24.00 \pm 2.010$ & 0.00 & PTA Lt AC 125 3rd trimester & 0.00 \\
\hline PTA AC 125 after delivery & $18.00 \pm 2.462$ & 0.00 & PTA Lt AC 125 after delivery & 0.00 \\
\hline \multicolumn{5}{|l|}{ PTA at $250 \mathrm{Hzs}$} \\
\hline PTA AC 250 1st trimester & $18.00 \pm 2.462$ & - & $18.00 \pm 2.462$ & - \\
\hline PTA AC 250 2nd trimester & $21.00 \pm 2.462$ & 0.00 & $21.00 \pm 2.010$ & 0.00 \\
\hline PTAAC 250 3rd trimester & $23.00 \pm 2.462$ & 0.00 & $23.00 \pm 2.462$ & 0.00 \\
\hline PTA AC 250 after delivery & $16.00 \pm 2.010$ & 0.00 & $16.00 \pm 2.010$ & 0.00 \\
\hline \multicolumn{5}{|l|}{ PTA at $500 \mathrm{Hzs}$} \\
\hline PTA AC 500 1st trimester & PTA Rt AC 500 1st trimester & - & $18.00 \pm 2.462$ & - \\
\hline PTAAC 500 2nd trimester & PTA Rt AC 500 2nd trimester & 0.00 & $18.00 \pm 2.462$ & 0.00 \\
\hline PTAAC 500 3rd trimester & PTA Rt AC 500 3rd trimester & 0.00 & $21.00 \pm 2.462$ & 0.00 \\
\hline PTA AC 500 after delivery & PTA Rt AC 500 after delivery & 0.00 & $15.00 \pm 0.000$ & 0.00 \\
\hline \multicolumn{5}{|l|}{ PTA at $1000 \mathrm{Hzs}$} \\
\hline PTAAC 1000 1st trimester & $16.00 \pm 2.010$ & - & $16.00 \pm 2.010$ & - \\
\hline PTAAC 1000 2nd trimester & $16.00 \pm 2.010$ & 0.00 & $16.00 \pm 2.010$ & 0.00 \\
\hline PTAAC 1000 3rd trimester & $19.00 \pm 3.761$ & 0.00 & $18.00 \pm 4.020$ & 0.00 \\
\hline PTA AC 1000 after delivery & $15.00 \pm 0.000$ & 0.00 & $15.00 \pm 0.000$ & 0.00 \\
\hline \multicolumn{5}{|l|}{ PTA at $2000 \mathrm{Hzs}$} \\
\hline PTA AC 2000 1st trimester & $15.00 \pm 0.000$ & - & $15.00 \pm 0.000$ & - \\
\hline PTA AC 2000 2nd trimester & $15.00 \pm 0.000$ & 0.000 & $15.00 \pm 0.000$ & 0.000 \\
\hline PTA AC 2000 3rd trimester & $15.00 \pm 0.000$ & 0.000 & $15.00 \pm 0.000$ & 0.000 \\
\hline PTAAC 2000 after delivery & $15.00 \pm 0.000$ & 0.000 & $15.00 \pm 0.000$ & 0.000 \\
\hline \multicolumn{5}{|l|}{ PTA at $4000 \mathrm{Hzs}$} \\
\hline PTAAC 4000 1st trimester & $15.00 \pm 0.000$ & - & $15.00 \pm 0.000$ & - \\
\hline PTAAC 4000 2nd trimester & $15.00 \pm 0.000$ & 0.000 & $15.00 \pm 0.000$ & 0.000 \\
\hline PTAAC 4000 3rd trimester & $15.00 \pm 0.000$ & 0.000 & $15.00 \pm 0.000$ & 0.000 \\
\hline PTA AC 4000 after delivery & $15.00 \pm 0.000$ & 0.000 & $15.00 \pm 0.000$ & 0.000 \\
\hline \multicolumn{5}{|l|}{ PTA at $8000 \mathrm{Hzs}$} \\
\hline PTA AC 8000 1st trimester & $15.00 \pm 0.000$ & - & $15.00 \pm 0.000$ & - \\
\hline PTAAC 8000 2nd trimester & $15.00 \pm 0.000$ & 0.000 & $15.00 \pm 0.000$ & 0.000 \\
\hline PTAAC 8000 3rd trimester & $15.00 \pm 0.000$ & 0.000 & $15.00 \pm 0.000$ & 0.000 \\
\hline PTA AC 8000 after delivery & $15.00 \pm 0.000$ & 0.000 & $15.00 \pm 0.000$ & 0.000 \\
\hline
\end{tabular}


In all pregnant women, the impedance tympanometry showed type I tympanograms (Type I, i.e., normal tympanograms).

\section{DISCUSSION}

Sex hormones exert regulatory influences on the central nervous system. The production rates for these hormones in nonpregnant women (estrogen $0.02-0.1 \mathrm{mg} / 24$ hours and progesterone $0.1-40 \mathrm{mg} / 24$ hours respectively) show considerable increase in near-term pregnant women (estrogen 50-100 mg/24 hours and progesterone 250-600 mg/24 hours). While creating optimal conditions for pregnancy, these hormonal changes cause an increase of $6.5 \mathrm{~L}$ in extracellular and $1.25 \mathrm{~L}$ in intracellular fluids. As a result of these osmotic changes in body, water and sodium retention takes place. As it is evident from previous studies that circulating sex hormones affect the sensorineural hearing system, one may expect changes in hearing levels with so much fluid retention during pregnancy. ${ }^{1}$

One of the main outcomes of this study is that while pregnancy does not affect the hearing acuity at high frequencies, there is a gradual decrease in hearing acuity at low frequencies $(125,250,500$, and $1000 \mathrm{~Hz})$ from 1 st to 3rd trimester $(\mathrm{p}<0.05)$ and return to normal in the postpartum period. Although there is a statistically significant difference with respect to mean pure tone thresholds between the different groups, this cannot be regarded as a hearing loss according to American National Standard Institute (ANSI). The result also demonstrates that there is no change in the hearing sensitivity between 2000 and $8000 \mathrm{~Hz}$ across different groups $(\mathrm{p}>0.05)$.

At frequencies 125 to $1000 \mathrm{~Hz}$, there is a statistically significant difference amongst the 1st to 3rd trimester groups (groups I, II, and III respectively) from group IV $(p<0.05)$. But at higher frequencies $(2000-8000 \mathrm{~Hz})$ no significant difference is measurable $(p>0.05)$. Another key finding of this study is that there is no significant difference amongst primigravida and multigravida in all trimesters $(\mathrm{p}>0.05)$.

Our study compares well with Sennaroglu and Belgin, ${ }^{4}$ who also reported a gradual decrease in pure tone averages at 125, 250, and $500 \mathrm{~Hz}$ from 1st to 3rd trimester. This decrease returned to normal in the postpartum period. The result of this study also demonstrated that there is no change in the hearing sensitivity between 1000 and $8000 \mathrm{~Hz}$. Thus they opined that pregnancy does not affect the high-frequency hearing level ( $p>0.05)$. The study suggested that the low tone decrease in acuity level may be due to excessive water and salt retention during pregnancy, which increases as pregnancy progresses and water retention at term is $6.5 \mathrm{~L}$ whereas plasma volume is also increased to $1.25 \mathrm{~L}$.

Our study also compares well with Sharma et al, ${ }^{1}$ who in a double blind study reported a gradual decrease in pure tone averages at 125, 250,500, and $1000 \mathrm{~Hz}$ from 1 st to 3rd trimester and the hearing threshold get stabilized in the 3rd trimester and return to normal in the postpartum period. Furthermore, it was observed that there was a highly statistically significant difference of threshold during pregnancy (groups I, II, and III) from the postpartum (group IV), indicating that these metabolic/ hormonal changes which result in increased threshold are reversible.

Kanadys and Oleszczuk ${ }^{5}$ in his study presents a very rarely occurring case of sudden sensorineural hearing loss in a 23-year-old healthy nulliparous woman during an uncomplicated pregnancy. It has been hypothesized that hearing loss may be associated with increased activation of both blood coagulation and fibrinolysis ("hypercoagulable state") which occurs during normal pregnancy. This state may lead to vascular occlusion in the microcirculation of the inner ear by microemboli. It is necessary to take certain predisposing factors into consideration, such as fluid and sodium retention, emotional instability, situation anxiety, viral, and allergic changes.

In our study, none of the pregnant women presented with sudden sensorineural hearing loss.

Pawlak et $\mathrm{al}^{6}$ in a case report of a 25-year-old, 27-week pregnant primipara who was admitted to the Department of Otolaryngology with right-sided sudden hearing loss and tinnitus lasting 2 days. There was no associated vertigo, viral infection, or history of trauma or medication intake. She was a nonsmoker. Her previous medical history was unremarkable and the pregnancy was not complicated. Tonal audiometry revealed unilateral cochlear hypoacusis with hearing loss reaching $60 \mathrm{~dB}$ in 1000 and $2000 \mathrm{~Hz}$ frequencies. Two years after her first delivery, she was pregnant for the second time. During the 4th week of pregnancy, she felt sudden hearing loss on the opposite side than during the first time. Tonal audiometry manifested unilateral hypoacusis: The deepest hearing loss came to $60-40 \mathrm{~dB}$ in the frequencies 1500, 2000, 3000, and $4000 \mathrm{~Hz}$. The other ear was completely normal. Pregnancy causes not only physiological changes in metabolism, hormone status, and autonomic nervous system but also impact of emotional stress. Sex hormones influence the central nervous system and provoke changes in hearing levels. It was postulated that the sex hormone changes may increase thrombogenic risk and interrupt cochlear microcirculation, causing the development of sudden deafness. This study did not take into account the different stages of pregnancy, which we did in our study. 
Schmidt et $\mathrm{al}^{2}$ studied hearing and vestibular complaints in pregnant women and analyzed that hormonal dysfunctions in women during pregnancy can cause hearing and vestibular and cochlear disorders. The hormonal alterations which happen during menstrual cycle, gestation, and menopause can result in changes in homeostasis of labyrinthine fluids, since they have a direct influence on the enzymatic process and the action of neurotransmitters. The compromise of labyrinthine fluid characteristics as well as the interference with the sensitivity of enzyme receptors influences the basal metabolism of inner ear, which can justify otological symptoms in women.

Hou et $\mathrm{ll}^{7}$ sudden sensorineural hearing loss (SSNHL) may occur during pregnancy, but its prevalence is very low. It is conjectured that SSNHL is closely related to the changes in the cardiovascular system, hematological system, endocrine system, and/or some other systems due to pregnancy. These changes possibly evoke disorders of cochlear circulation or cochlear fluid homeostasis leading to SSNHL. Based on their distinct clinic profiles, a new disease, called "pregnancy-induced sudden sensorineural hearing loss," was coined.

\section{CONCLUSION}

From this study it can be concluded that the pregnancyrelated changes that occur in audiological functions need further investigation. The low frequency hearing loss observed appear to be transient in nature and is most marked during the pregnancy with complete resolution in postpartum period in most cases, indicating that all subjective complaints of these symptoms during pregnancy are physiological and not pathological. The number of pregnancies a female undergoes does not appear to affect these symptoms.

Thus, for a better understanding of these changes, both the otolaryngologist and obstetrician can team up to improve the quality of life of pregnant subject by avoiding use of drugs for their symptoms during pregnancy especially in the 1st trimester.

\section{REFERENCES}

1. Sharma K, Sharma S, Chander D. Evaluation of audiorhinological changes during pregnancy. Indian J Otolaryngol 2011 Jan;63(1):74-78.

2. Schmidt PM, Flores Fda T, Rossi AG, Silveira AF. Hearing and vestibular complaints during pregnancy. Braz J Otorhinolaryngol 2010 Jan-Feb;76(1):29-33.

3. Kenny R, Patil N, Considine N. Sudden (reversible) sensorineural hearing loss in pregnancy. Ir J Med Sci 2011 Mar;180(1):79-84.

4. Sennaroglu G, Belgin E. Audiological findings in pregnancy. J Laryngol Otol 2001 Aug;115(8):617-621.

5. Kanadys WM, Oleszczuk J. Sudden sensorineural hearing loss during pregnancy. Ginekol Pol 2005 Mar;76(3):225-227.

6. Pawlak-Osinska OK, Burduk PK, Kopczynski A. Episodes of repeated sudden deafness following pregnancies. Am J Obstet Gynecol 2009 Apr;200(4):e7-e9.

7. Hou ZQ, Wang QJ. A new disease: pregnancy-induced sudden sensorineural hearing loss? Acta Otolaryngol 2011 Jul;131(7):779-786. 